\title{
RESEARCH ON URBAN RENEWAL FROM THE PERSPECTIVE OF NATURAL DISASTER VULNERABILITY
}

\author{
PENG CHENG XIANG ${ }^{1,2}$, YI MING WANG ${ }^{1} \&$ QING DENG ${ }^{1}$ \\ ${ }^{1}$ School of Construction Management and Real Estate, Chongqing University, China \\ ${ }^{2}$ International Research Centre Sustainable Built Environment, China
}

\begin{abstract}
At present, economic development has become a dominant factor in the promotion of urban renewal in China. This means that decision-makers often overlook the impact of the natural environment on the urban renewal of the region. This paper begins with a review of the literature concerning urban renewal and natural disaster vulnerability in order to discuss the mechanism of interaction between natural disasters and urban renewal. Then, an evaluation model of natural disaster vulnerability in urban areas is constructed, and a DEA model is used to assess the vulnerability of natural disasters in various regions of a city. Finally, using the idea of regional planning, this paper puts forward a method for urban renewal, taking natural disaster factors into consideration, and provides an important direction for urban renewal in order to realize the sustainable development of cities. The findings of this paper substantiate the phenomenon that, at this stage, urban renewal has brought many problems. Although urban renewal enhances the city's resilience to natural disasters, understanding how to assess the vulnerability of natural disasters in all regions of the city has been a challenge and should be part of an integrated planning approach. This paper puts forward the countermeasure of urban renewal against the background of natural disaster, from the perspective of sustainable development.

Keywords: urban renewal, natural disaster, vulnerability, DEA.
\end{abstract}

\section{INTRODUCTION}

At present, China is one of the fastest growing economies in the world, and sustained economic growth has contributed to the process of urban renewal. This is mainly embodied in the following two aspects: One is the development of new areas for city expansion and the other is urban renewal, featuring large-scale demolition and reconstruction in order to make full use of scarce land downtown under the influence of economic development.

However, from a sustainable development perspective, large-scale demolition and construction in the city is an unsustainable development path. In her book, The Death and Life of Great American Cities, Jacobs [1] points out that "Large-scale projects can only benefit architects, politicians and real estate developers, but the masses always become victims."

Urban renewal is an economic activity, which can promote China's modernization and urbanization, but it is also a social behaviour. From the perspective of natural disasters, urban renewal requires the attention of all sectors of society. Urban renewal is not only a matter of improving the physical environment but also a profound social change that involves the spatial structure of the city. Inappropriate guidance will be counterproductive and will lead to a wider social crisis. Therefore, how to effectively carry out urban renewal in areas at risk of natural disasters has become the main problem of urban construction.

In order to provide a research context, the key issue examined in the literature review is urban renewal in the context of natural disaster risk. Subsequently, taking account of the interaction between urban renewal and natural disasters, the mechanism of urban renewal and natural disaster is studied. Then, through a DEA model, which assesses the vulnerability to natural disasters in various urban regions, Chongqing is selected as the case for empirical 
analysis. Finally, urban renewal strategies, based on the vulnerability to natural disasters are put forward.

\section{LITERATURE REVIEW}

\subsection{The concept of urban renewal}

The first urban renewal seminar [2], which was held in the Netherlands in August 1858, gave a relevant explanation of urban renewal: "The public have different expectations and dissatisfactions with their buildings, living environment, travel, shopping, entertainment and other activities; they have high hopes of improving their own neighbourhoods, streets and parks to have a comfortable living environment and a beautiful city". Since then, there has been continuous study of urban renewal by domestic and foreign scholars, but the academic community is yet to form a clear definition for the concept of urban renewal. Chen [3] defines urban renewal as a process of "metabolism". Wu [4] puts forward the concept of "organic renewal", from the perspective of "protection and development", and emphasizes the city's material environment, while ignoring social and cultural factors. Zhang [5] argues that, with the rapid development of urbanization, there has been an increase in urban problems, so we should formulate corresponding urban policies to solve them. Cheng and Zhang [6] suggest that we are in a global context and that the purpose of renewal is to increase the competitiveness of the city as a whole. $\mathrm{Wu}$ [7] proposes considering the overall development of the city from economic, social and environmental aspects, so as to improve the urban structure. $\mathrm{Yu}$ [8] emphasizes the overall development of the declining areas. He proposes not only to improve the material environment, but also to consider the improvement of its nonmaterial environment, such as the neighbourhood social network structure, psychological set, emotional attachment and so on. Urban renewal is usually referred to as urban regeneration in Europe [9], and as urban revitalization in the United States [9]; Both of which refer to the process of high intensity redevelopment of areas where urban land use is relaxed. Roberts [10] defines it as an integrated, holistic approach to solving a wide range of urban problems. Hausner [11] suggests that the process of urban renewal should not only broaden horizons but also reflect the characteristics and needs of specific cities or sectors themselves. These different expressions show scholars' focus and understanding of urban renewal from different perspectives. Based on the definitions of scholars from home and abroad, urban renewal is the necessary and planned renovation and reconstruction of areas, which cannot adapt to the sustainable development of the modern city.

\subsection{The concept of natural disaster vulnerability}

Simultaneously with the process of urbanization and large-scale unplanned expansion, the risk of natural disasters faced by large cities is increasing. Research at the Centre for International Earth Science Information Network (CIESIN) [12] shows that 900 million people in 450 of the world's 633 megacities are exposed to at least one disaster risk. And when the risk occurs, social and economic losses also tend to increase in proportion to the size of the city's expansion. In view of this, scholars have also paid great attention to natural disasters. In the field of disaster research, the concept of vulnerability is one that divides scholars. The International Strategy for Disaster Reduction (ISDR) [13] considers that vulnerability is a reflection of the ability to withstand disasters, which is determined by nature, society, economy and environment. Considering that the purpose of vulnerability research is ultimately to aid decision-making. Cannon [14] argues that vulnerability is a 
greater predictor than terms showing present situations, such as poverty and is an explanation of the consequences for specific groups of people under specific hazards and conditions of risk. The United Nations University Institute for Environment and Human Security (UNUEHS) [15] offers a relatively new concept: namely, that vulnerability is the internal and dynamic characteristics of the risk recipient (community, region, country, infrastructure, environment, etc.) and determines the expected loss under specific disasters. Vulnerability is determined by nature, society, economy and environment and changes over time. This shows that different research areas have differing focuses on vulnerability; among these, natural science focuses on the consequences of the individual or the system, while social science focuses on factors from the society, economy and other aspects that caused the vulnerabilities. Crichton [16] points out that the relationship between risk and vulnerability is "risk = hazard $\times$ exposure $\times$ vulnerability". Shi [17] believes that disasters are composed of four parts: disaster-causing factors, disaster-inducing environment, disaster-bearing body and conditions of disaster.

In summary, the concept of vulnerability to natural disasters should be understood in two dimensions: one is whether the disaster-bearing body is the system or individual, and the other is whether the origin of the fragility is analysed from the perspective of the physical attributes of the disaster-bearing body or from a social point of view.

\section{ANALYSIS OF THE MECHANISM OF NATURAL DISASTER AND URBAN RENEWAL}

\subsection{The impact of urban renewal on natural disasters}

Urban renewal involves a complicated change of spatial form and the process of social and economic development. It is common for urban areas to suffer problems such as overexploration of underground water, natural vegetation degradation, low vegetation coverage and water pollution. In most developing countries, the urban renewal process is taking place too fast, and the urban population is expanding, causing serious environmental problems and disasters. In order to survive, people have become more and more demanding in their transformation of the natural ecological environment; thus, the extreme vulnerability of an arid ecological environment is fully revealed, leading to a vicious circle of urban renewal and natural disasters.

- The nature of the underlying surface of the city has changed, causing floods and other natural disasters. Due to the large amount of construction in the city, growing space for green vegetation is limited and vegetation coverage is being reduced. Maintaining the balance of the ecosystem is an important factor in protecting the natural environment. The loss of vegetation will mean that the city fails in the important function of protecting the natural environment, and the number of natural disasters will gradually increase.

- With the acceleration of urbanization, the destruction of the ecological environment has increased the intensity and frequency of natural disasters, expanding the area affected by natural disasters and extending the duration of natural disasters. For areas with frequent flood disasters, the increase of urbanization will increase the area of impervious hard ground, blocking rainwater infiltration channels, which will increase the intensity of flood disaster. 


\subsection{The impact of natural disasters on urban renewal}

Natural disasters are natural events, causing the loss of people's lives and property, that occur in a certain natural environment and are beyond human ability to control. They are the product of the interaction between nature and the human socio-economic system. Natural disasters mainly focus on forces of nature, but they are closely related to human socioeconomic activities. Compared to other regions, cities have more concentrated population and assets so they are under greater threat from natural disasters. Natural disasters affect the improvement of social productive capacity and cause the reduction of social wealth, ultimately restricting the long-term economic development of society. Natural disasters vary with the increase in population, improvements in science and technology, the development of society and the extent that human beings take advantage of the natural resources. The scale of the city increases with the process of urbanization, and losses caused by natural disasters are increasing constantly. Natural disasters have limited the economic development of the affected areas and widened the economic gap between them and other regions. The greater the economic gap is, the greater the impact it has on social stability. This is a vicious circle: the ecological environment becomes more fragile and the affected areas become poorer. The occurrence of natural disasters undermines the harmonious conditions of human existence and development. The impact of natural disasters is multifaceted, and the occurrence of a natural disaster can have many different negative effects.

1. Natural disasters increase the city's economic losses. Urban assets are highly intensive so that the city's integrated disaster capacity is relatively weak. Natural disasters destroy constructions, such as houses and bridges, and interrupt the city's transportation, electricity, water, telecommunications and financial information network, leading to an increase in indirect economic losses in various fields such as industry, commerce, service industries and foreign trade. Furthermore, natural disasters create direct economic losses for individuals and public organizations; they have long-term negative effects on regional economic development, such as the slowdown of economic growth and more uneven regional economic development.

2. Natural disasters damage environmental resources. The environment of the city is labouring under pollution, and the quality of the environment degrades, causing severe social impact. Environmental resources are important for the development of the city, so their destruction will cause slow or no regional economic development for a while. The damage caused to the environment by natural disasters increases the cost of environmental protection. Economic losses caused by natural disasters increase the cost of restoring and rebuilding the city. Natural disasters damage the good living environment of city dwellers, lower their quality of life and influence the steady improvement of urbanization.

3. Natural disasters cause casualties and slow down the urban renewal process. Human life and health are endangered by natural disasters, which also disrupt the normal life order. Urban renewal is inseparable from the participation of people, and economic growth requires people to create it, but casualties will affect the regional economic development, thus affecting the process of urbanization. Especially when victims lose their families after natural disasters, it is easier to become depressed, pessimistic and desperate under the circumstances of no water or electricity and no home to return to. The negative emotions caused by natural disasters affect the recovery and reconstruction of cities and the development of urbanization. 


\section{EVALUATION MODEL OF NATURAL DISASTER VULNERABILITY IN URBAN AREAS}

Over the past decade, the implementation of the International Strategy for Disaster Reduction has shown that prevention is the most important of the three aspects of prevention, preparedness and mitigation. Disaster risk assessment is a quantitative analysis and assessment of the potential consequences of disaster risk areas at different intensities. Because the system of vulnerability to natural disasters is too large and the disaster types are complex, this paper uses a Data envelopment analysis (DEA) model to evaluate the vulnerability of natural disasters. Based on the analysis of the applicability of a DEA model to natural disaster vulnerability assessment, the fragility evaluation index system of regional disaster is constructed. The regional fragility level of natural disasters in the main urban area of Chongqing is quantitatively studied in order to provide scientific reference for the formulation and adjustment of regional disaster mitigation policies.

\subsection{Construction of DEA model}

Data envelopment analysis (DEA) is a well-established methodology to evaluate the relative efficiencies of a set of comparable entities by some specific mathematical programming models. A main advantage of DEA is that it does not require any prior assumptions on the underlying functional relationships between inputs and outputs.

In this paper, the classical C2R model of DEA is used for analysis. There are decisionmaking units $\left(D M U_{j}\right)(j=1,2, \ldots, n)$, with each $D M U_{j}$ having the same $m$ inputs and outputs. The input vector is $X_{j}=\left(x_{1 j}, x_{2 j}, \ldots, x_{m j}\right) T$, the output vector is $Y_{j}=\left(y_{1 j}, y_{2 j}, \ldots, y_{s j}\right) T$, and the $\mathrm{C} 2 \mathrm{R}$ dual input model for regional natural disasters' vulnerability assessment is as follows:

$$
\text { s.t. }\left\{\begin{array}{c}
\min \left[\theta-\varepsilon\left(e^{t} S^{-}+e^{t} S^{+}\right)\right. \\
\sum_{j=1}^{n} X_{j} \lambda_{j}+S^{-}=\theta X_{0} \\
\sum_{j=1}^{n} X_{j} \lambda_{j}-S^{+}=Y_{0} \\
\lambda_{j} \geq 0, S^{-} \geq 0, S^{+} \geq 0, j=1,2,3 \ldots, n
\end{array}\right.
$$

In eqns $(1) \sim(2): \theta(0<\theta \leq 1)$ is the comprehensive technical efficiency index of the DEA model; $\lambda$ is the weight change quantity; $S^{-}$is the relaxation variable; $S^{+}$is the residual variable; $\varepsilon$ is the non-Archimedes infinitesimal amount, generally take $\varepsilon=10^{5}$. According to the meaning of the DEA model, the closer the value of the regional evaluation unit, $\theta$, to 1 , the higher will be both the input-output ratio of the decision-making unit and the production efficiency level of the unit. Under the analysis of the input-output of the natural disaster system, it can be considered that the disaster efficiency of the evaluation unit is higher, which means that the region is highly vulnerable; otherwise, it is an area with a low level of vulnerability. When $\theta=1$, this indicates that the input-output operation level of this region is on the optimal production frontier, and the output of the region has optimal comprehensive efficiency, compared to the input. This means that the damage effect of the region under natural disasters reaches its maximum, and the regional vulnerability level under natural disasters is the highest.

\subsection{The selection of indicators and data processing}

The occurrence of natural disasters is the result of the synergistic effect of regional natural disaster system elements, including disaster-inducing factors, the exposure of regional resources and property, the ability of the disaster-affected body to coordinate and adapt, and the sensitivity of regional resources and property. However, each factor has a different effect on the occurrence of disasters. Disaster-inducing factors have natural attributes and are 
inevitable. In respect of the exposure of regional resources and property, the ability of the hazard-affected body to coordinate and adapt, and the sensitivity of regional resources and property, human factors play an important role. If the same kind of disaster occurs in different regional bodies with the same intensity, it will cause different results. The balance between the human and social environment can affect the seriousness of the disaster. This unbalanced situation can be improved through the planning and management of human activities; therefore, this shows that the vulnerability of the hazard-affected body is relative and can change with human activities. Therefore, the occurrence of the disaster is caused by disasterinducing factors, the exposure of vulnerable property of the regional hazard-affected body, the coordination of the region's disaster-bearing capacity and regional resources and property sensitivity. This paper will calculate the regional vulnerability level by using the following three aspects as input-output factors of the DEA model: regional disaster risk, regional exposure level and regional disaster comprehensive loss. According to the Regional Atlas of Chinese Typical Counties (Cities) Prone to Geological Disasters Southwest Volume and the China Statistical Yearbook, the selected input and output factors of the model evaluation indicators are as shown in Table 1, taking Chongqing city as the basic evaluation unit.

Table 1: Selection and processing of evaluation index in DEA model. for vulnerability assessment.

\begin{tabular}{|c|c|c|c|}
\hline & $\begin{array}{l}\text { Regional Disaster } \\
\text { Risk Index }\end{array}$ & $\begin{array}{c}\begin{array}{c}\text { Exposure Level of } \\
\text { Regional Hazard- } \\
\text { Bearing Body }\end{array} \\
\end{array}$ & $\begin{array}{c}\text { Regional Disaster } \\
\text { Comprehensive Loss } \\
\text { Degree }\end{array}$ \\
\hline $\begin{array}{l}\text { Indicator } \\
\text { Meaning }\end{array}$ & $\begin{array}{l}\text { Determined by } \\
\text { disaster-inducing } \\
\text { factors and } \\
\text { vulnerability of } \\
\text { regional hazard- } \\
\text { bearing body }\end{array}$ & \begin{tabular}{|c|} 
Vulnerable resources \\
and property, such as \\
population, houses, land \\
and roads, exposed to \\
natural disasters. The \\
more exposed they are, \\
the more potential \\
losses there will be
\end{tabular} & $\begin{array}{l}\text { Loss assessment after } \\
\text { the natural disaster, } \\
\text { such as casualties, the } \\
\text { number of collapsed } \\
\text { houses and direct } \\
\text { economic losses }\end{array}$ \\
\hline $\begin{array}{l}\text { Selection of } \\
\text { Evaluation } \\
\text { Index }\end{array}$ & $\begin{array}{l}\text { Mountain disaster } \\
\text { (landslide, collapse, } \\
\text { debris flow), drought, } \\
\text { rainstorm flood }\end{array}$ & \begin{tabular}{|c|} 
\\
Regional total \\
population, GDP, GDP \\
per capita, population \\
density, regional \\
urbanization level \\
\end{tabular} & $\begin{array}{c}\text { Disaster area, died-out } \\
\text { areas, the total } \\
\text { population affected, } \\
\text { the number of deaths } \\
\text { due to the disaster, the } \\
\text { number of collapsed } \\
\text { houses, direct } \\
\text { economic losses } \\
\end{array}$ \\
\hline $\begin{array}{l}\text { Data } \\
\text { Processing } \\
\text { Method }\end{array}$ & $\begin{array}{c}\text { The mean-weighted } \\
\text { summation is used as } \\
\text { input to the DEA } \\
\text { model }\end{array}$ & $\begin{array}{c}\text { Factor analysis method } \\
\text { is used to } \\
\text { extract the principal } \\
\text { component factors as } \\
\text { input factors of the } \\
\text { DEA model }\end{array}$ & $\begin{array}{c}\text { Factor analysis } \\
\text { method is used to } \\
\text { extract the principal } \\
\text { component factors as } \\
\text { the output factor of the } \\
\text { DEA model }\end{array}$ \\
\hline Data Sources & References & $\begin{array}{c}\text { China Statistical } \\
\text { Yearbook } \\
\text { 2001 2008 }\end{array}$ & \begin{tabular}{|} 
Statistical Yearbook of \\
China's Civil \\
Administration \\
$2001 \sim 2008$
\end{tabular} \\
\hline
\end{tabular}


Some research experts have selected the evaluation index from the three aspects: disasterinducing environment, natural disaster-inducing factors and disaster bearing bodies, according to the theory of natural disaster system; they obtained the Chongqing hazardinducing environment sensitivity map, the risk of natural disaster-inducing factors map, and the vulnerability map of the regional hazard-bearing body through Geographic Information System (GIS) analysis. This paper analyses the regional disparity of natural disasters in Chongqing and carries out comprehensive regionalization of natural disasters, in order to obtain four natural disaster areas. Based on the principle of the above-mentioned zoning, the main urban areas of Chongqing are selected as the research area, and the disaster risk index is calculated by assigning 1 to 5 as the regional hazard coefficient. Due to the stochastic nature of natural disasters, the inter-annual fluctuation of the statistical indicators of disaster losses is large, and it is not easy to use the data of disaster damage at a certain point in time to compare the regional vulnerability levels. But in a period of time, the mean of natural disaster losses shows a certain stability, so it can be used to compare levels of regional damage losses. In order to maintain the consistency of input and output indicators, regional exposure indicators will also use the average for many years.

Using Statistical Product and Service Solutions (SPSS) to analyse the principal components of the original data of natural disaster exposure and disaster damage degree, we can extract two principal components (Table 2). According to their load distribution, it is clear that the principal components of regional exposure show characteristics of regional exposure through density exposure and total exposure, while the principal components of regional disaster damage depict regional losses through population property losses and

Table 2: Vulnerability assessment for regional natural disasters of Chongqing.

\begin{tabular}{|c|c|c|c|c|c|c|}
\hline \multirow{2}{*}{$\begin{array}{l}\text { District of } \\
\text { Chongqing }\end{array}$} & \multicolumn{2}{|c|}{$\begin{array}{c}\text { Regional Exposure } \\
\text { Level }\end{array}$} & \multirow{2}{*}{$\begin{array}{c}\text { Regional } \\
\text { Disaster } \\
\text { Risk }\end{array}$} & \multicolumn{2}{|c|}{$\begin{array}{l}\text { Regional Disaster } \\
\text { Damage Degree }\end{array}$} & \multirow{2}{*}{$\begin{array}{c}\text { Disaster } \\
\text { Efficiency } \\
\text { (Vulnerability) }\end{array}$} \\
\hline & $\begin{array}{l}\text { Density } \\
\text { Exposure }\end{array}$ & $\begin{array}{c}\text { Total } \\
\text { Exposure }\end{array}$ & & $\begin{array}{l}\text { Population } \\
\text { Property } \\
\text { Losses }\end{array}$ & $\begin{array}{l}\text { Agricultural } \\
\text { Losses }\end{array}$ & \\
\hline $\begin{array}{l}\text { Yuzhong } \\
\text { District }\end{array}$ & 1.48 & 1.95 & 3.00 & 3.47 & 2.32 & 1.000 \\
\hline $\begin{array}{c}\text { Yubei } \\
\text { District }\end{array}$ & 3.07 & 1.64 & 3.60 & 1.25 & 1.22 & 0.499 \\
\hline $\begin{array}{l}\text { Jiangbei } \\
\text { District }\end{array}$ & 2.79 & 1.40 & 3.40 & 1.17 & 1.55 & 0.639 \\
\hline $\begin{array}{l}\text { Shapingba } \\
\text { District }\end{array}$ & 1.49 & 3.75 & 3.80 & 2.28 & 3.45 & 0.719 \\
\hline $\begin{array}{c}\text { Jiulongpo } \\
\text { District } \\
\end{array}$ & 1.36 & 2.29 & 3.40 & 2.29 & 3.18 & 0.853 \\
\hline $\begin{array}{c}\text { Dadukou } \\
\text { District }\end{array}$ & 1.32 & 2.47 & 2.20 & 1.56 & 1.78 & 0.678 \\
\hline $\begin{array}{l}\text { Nan'an } \\
\text { District }\end{array}$ & 3.27 & 2.08 & 3.58 & 3.21 & 2.39 & 0.926 \\
\hline $\begin{array}{c}\text { Beibei } \\
\text { District }\end{array}$ & 3.03 & 1.47 & 3.72 & 2.03 & 3.67 & 0.861 \\
\hline $\begin{array}{c}\text { Banan } \\
\text { District }\end{array}$ & 2.90 & 2.80 & 3.67 & 2.71 & 2.98 & 0.907 \\
\hline
\end{tabular}


agricultural losses. The score of factors obtained from the analysis of the principal components and the reduction of original variables might be negative, while the output value of the DEA model cannot be negative, so the data should be the converse. The original data series is linearly transformed to a new data interval [1], [5] by using the min-max normalization method, and a new data series is formed. The formula is: $\mathrm{V}=\left(\mathrm{V}-\min _{A}\right) \div$ $\left[\max _{A}-\min _{A}(N\right.$ ew-maxA$-N e w-\min A)+N$ ew-minA $]$.

Based on the Chongqing Statistical Yearbook, the governmental work report and the statistics on environmental emergencies in Chongqing, this paper selects the data regarding natural disasters in the nine districts of the urban area of Chongqing in the last ten years. Then the relevant data of natural disasters' input index and output index in the main urban areas of Chongqing are put into the C2R model. Deap2.1 software is used to calculate vulnerability to natural disasters in the nine main urban areas of Chongqing (Table 2), so the urban renewal planned in the nine main urban areas of Chongqing can be more specific.

\subsection{Results analysis}

From Table 2, we can see that the vulnerability to natural disasters differs in the nine districts of Chongqing. The probability of natural disasters in Yuzhong, Nan'an and Banan is greater, mainly due to the natural environment and economic development of those areas. For example, Yuzhong District, as the core area of urban development in Chongqing, has a relatively low risk of natural disasters. However, due to its high degree of disaster damage, natural disasters have a greater impact on its urban renewal and reconstruction. In Chongqing's current urban renewal, the key area is still the old town, in which to some extent the risk of natural disasters is not great. The purpose of the government's renovation in these areas is mainly to promote regional economic development, rather than to prevent natural disasters and protect the personal safety and property of the residents. Taking Yuzhong District as an example, its urban renewal area at present mainly concentrates on Shibati area. The renovation of this area is mainly aimed at the economic development of Yuzhong District, without taking into account other more serious natural disasters. In the process of urban renewal, policy makers pay too much attention to the development of the urban economy, while other factors are ignored, which is extremely unfavourable to the sustainable development of the city.

\section{CONCLUSION}

This paper defines the concept of urban renewal and natural disaster vulnerability, which lays the foundation for the ensuing analysis of the mechanism of urban renewal and natural disaster vulnerability. Taking Chongqing as an example, this paper gives a quantitative analysis of the vulnerability to natural disasters of nine main urban areas in Chongqing, through a DEA model, and puts forward a new view of an urban renewal model, based on vulnerability to natural disasters, which is conducive to the sustainable development of society.

\section{REFERENCES}

[1] Jacobs, J., American City Life and Death. Yilin Press: Nanjing, pp. 986-996, 2014.

[2] Hong, L.L., Wang, A. et al., Evaluating the Performance of Public Involvement for Sustainable Urban Regeneration. Procedia Engineering, 145, pp. 1493-1500, 2016.

[3] Chen, Z.X., Conclusion of the Principles of Urban Planning and Design - The Machu Picchu Charter. Urban Planning, 6, pp. 75-84, 1979. 
[4] Wu, L.Y., Beijing Old City and Juer Alley. China Building Industry Press: Beijing, pp. 103-112, 1994.

[5] Zhang, P.Y., Urban Regeneration: The Trend of Urbanization in China in the 21st Century. Progress in Geography, 4, pp. 72-79, 2004.

[6] Cheng, D.L. \& Zhang J.X., Urban Renewal: Beyond the Material Planning Action and Thinking. City Planning, 2, pp. 70-73, 2004.

[7] Wu, C., Urban Revival Theory Analysis. Beijing Planning and Design, 1, pp. 140-143, 2005.

[8] Yu, J., Online. http://blog.sina.com.cn/s/blog_5715a19c0102e6sx.html.

[9] Jongeneel-Grimen, B., Droomers, M., Kramer, D. et al., Impact of a Dutch Urban Regeneration Programme on Mental Health Trends: A Quasi-Experimental Study. Journal of Epidemiology and Community Health, 7(1), pp. 15-25, 2016.

[10] Roberts, P., Evolution, Definition and Purpose of Urban Regeneration. SAGE Publications: London, pp. 9-36, 2000.

[11] Hausner, V.A., Future of Urban Development. Royal Society of Arts Journal, 141, pp. 523-533, 1993.

[12] Meng, Y.C., Wang Z., Wu, J.D. et al., Global Impacts of Catastrophes: A Case Study of the Economic Impacts of the Great East Japan Earthquake. Journal of Natural Disasters, 24(6), pp. 1-8, 2015.

[13] Lu, Z.H. \& Cui, Q.W., Study on Sustainable Disaster Reduction Strategy in the United States. World Earthquake Translation, 2, pp. 64-70, 2007.

[14] Cannon, W.B., Bodily Changes in Pain, Hunger, Fear, and Rage: An Account of Recent Researches into the Function of Emotional Excitement. Appleton and Company: New York, pp. 28-35, 1915.

[15] Wang, Y., Fang, C.L. \& Zhang, Q., Urban Vulnerability Research Review and Prospect. Journal of Geographical Science, 32(5), pp. 755-768, 2013.

[16] Crichton, D., The Risk Triangle. Natural Disaster Management. Tudor Rose: London, 1999.

[17] Shi, P.J., Theory and Practice of Disaster Research [J]. Journal of Natural Disasters, 5(4), pp. 6-14, 1996. 